\title{
Critical Incidents in Graduate Student Development of Multicultural and Social Justice Competency
}

\author{
Sandra Collins \\ Athabasca University, Canada \\ E-mail: sandrac@athabascau.ca \\ Nancy Arthur \\ University of Calgary, Canada \\ E-mail narthur@ucalgary.ca \\ Candace Brown \\ Athabasca University, Canada \\ E-mail: shane.candace@yahoo.ca
}

\section{Doi:10.5901/ajis.2013.v2n9p105}

\section{Abstract}

In many countries, counselling psychology has increasingly attended to the diverse needs of clients within multicultural societies. In North America, emphasis has been placed on nondominant populations, whose experiences of discrimination, cultural oppression, and social, economic, and political marginalization, have a significant impact on psychosocial wellbeing. Counsellors are expected to engage in social justice action, with or on behalf of clients, to effect change in organizations, communities, or broader social systems. The purpose of this study was to examine how well counsellor education programs in Canada are preparing counsellors for both multicultural counselling and social justice. Most research has focused on curriculum content; less attention has been paid to how that content is taught and the efficacy of those learning processes in facilitating competency. The critical incident technique was used to solicit examples of effective and less effective learning processes from graduate students. The qualitative data was analyzed to isolate, cluster, and relate emergent concepts; a critical lens also highlighted missing constructs. The most common learning contexts were the multicultural counselling course and the applied practicum. Four themes emerged that reflect current research: fostering of self-awareness, application of theory to practice, engagement of affect through experiential exercises, and exposure to diversity. Infusion of multicultural and social justice competency throughout curricula is also widely advocated, but was reflected in only four percent of the critical incidents. Engagement in social justice roles and activities was also missing. Enhancements to both curriculum content and process are required to support the social justice agenda.

\section{Introduction}

Over the last decade, researchers in the area of multicultural counselling, feminist theory, and other disciplines have increasingly focused their attention outward to interpersonal and community influences, contexts of people's lives, and broader systemic influences on individuals and communities (Greenleaf \& Williams, 2009; Hage\& Kenny, 2009).The traditional focus on intrapsychic factors in health and wellness is limiting and potentially damaging to clients, because it fails to take into account the social determinants of health, in particular, the impact of social injustices (Fowers and Davidov, 2007; Sinacore et al., 2011).These injustices include: unfair and inequitable distribution of resources and opportunities; discrimination, oppression, and marginalization in society; and barriers to basic human rights and attainment of full potential in society (Arthur, Collins, McMahon, \& Marshall, 2009; Green, McCollum \& Hays, 2008).

These social injustices arealso strongly tied to cultural group affiliation, based on ethnicity, gender, sexual orientation, ability, age, socioeconomic status, and religion. Those with nondominant identities more often face active or passive discrimination in Western society (Arthur \& Collins, 2011; Leong, 2010), and the potential for socio-cultural oppression and marginalization increases with multiple non-dominant identities (Collins, 2010a, 2010b). Broadening our definition of culture to include each of these cultural identity factors, and recognizing the close ties between social injustice and psycho-social well-being, has necessitated a shift in how counsellors view client problems and how those 
problems are addressed (Fowersand Davidov, 2007; Ratts, 2011; Sinacore et al., 2011). Increasingly, counsellors are called upon to engage in social justice work with and on behalf of their clients (Ratts\&Hutchkins, 2009).

Many counsellor education programs have embraced increased consciousness of cultural influences on both clients' lives and the counselling process (Constantine, Hage, Kindaichi, \& Bryant, 2007; Zalaquett, Foley, Tillotson, Dinsmore, \& Hof, 2008). However, most programs have not focused attention, to the same degree, on social justice as a critical lens in case conceptualization, intervention planning with individual clients, or expanding the scope of practice to include direct social justice action to ameliorate the conditionsthat bring clients into counselling in the first place (Alberta \& Wood, 2009; Constantine et al., 2007).There is also evidence that both students and practicing counsellors perceive a gap in their competency levels, particularly in the area of social justice action (Cates \&Schaefle, 2009; Pieterse, 2009; Pieterse, Evans, Risner-Butler, Collins, \& Mason, 2009). As social justice consciousness increases, there must be a corresponding shift in our education programs to prepare future counsellors for the complex challenge of fully meeting clients where they are at - within the community, institutional, societal, economic, and political systems that directly and indirectly influence their lives (Miville et al., 2009).

\section{Positioning the Study}

Research is lacking on the effectiveness of multicultural and social justice curriculum and, in particular, the relationship of that learning to applied practice contexts (Smith, Constantine, Dunn, Dinehart, \& Montoya, 2006; Vera \& Speight, 2003).The analysis in this article forms part of a larger research study that aimed to better understand how students, counsellors, and practicum site supervisors view multicultural counselling and social justice and how their professional education has prepared them to apply multicultural and social justice principles in practice. The data on counsellors and practicum supervisors are reported elsewhere (Collins, Arthur, \& Brown, 2013; Collins, Arthur, Brown, \& Kennedy, 2013a).In addition, we have chosen to focus this article only on students' descriptions of critical incidents (Cls) in their learning process to ensure that we have a sound understanding of what has been most influential for them to answer the question: How is counsellor education currently preparing students for multicultural counselling and social justice action?

There is considerable research and recommendations from accrediting bodies in both Canada and the United States on what should be included in counsellor education, albeit with gaps particularly in the area of social justice (Butler-Byrd Nieto, \& Nieto Senour, 2006; Toporek\& McNally, 2006). However, less attention has been focused on the process of counsellor education (Pieterse et al., 2009; Smith et al., 2006).This article highlights student voices in examining what learning methodologies, resources, tools, or processes are most memorable orprominent.

\section{Methodology}

Graduate students in two Canadian counsellor education programs were invited to participate in this study.The programs were selected because of their affiliations with the researchers and differences in learning format: traditional face-to-face program versus distributed learning program with substantive online learning components. Participants had completed the majority of their course work and were either nearing completion or had recently completed their practicum placement.Fifty-nine students participated in the overall study. Eighty-six percent of participants were spread equally over three age brackets, 29 years or less; 30 to 39 years; and 40 to 49 years, with the remaining 14\% between 50 and 59 years.Eighty-five percent of the participants were women, which is reflective of the gender distributions in the programs sampled.Eighty-one percent were Caucasian; one student was of Aboriginal decent; and nine others were from other ethnical backgrounds (South Asian, Chinese, African/Caribbean, Latin American, and Arabic).

Students were invited to complete an online survey, which involved identifying and reflecting on two $\mathrm{Cls}$ that described a significant education experience.Thirty-eight of 59 students provided the Cls reported in this article.A portion of these students agreed to further clarification of their ideas by email.In addition, a subset of eight students agreed to a semi-structured follow-up interview. The data from both the online survey and the follow-up interviews have been combined for this article. The critical incident technique (CIT) involves soliciting vignettes or short descriptive accounts from research participants about experiences that they deem as particularly important or illustrative of a particular phenomenon.The CITis common in contemporary research (Butterfield, Borgen, Amundson, \&Maglio, 2005) and has been used, for example, to examine development of social justice perspectivesof doctoral students (Caldwell \& Vera, 2010), outcomes of a multicultural counselling course (Sammons \& Speight, 2008), andthe social justice competencies of career counsellors (Arthur, Collins, Marshall, \& McMahon, 2013).Inviting students to generate Cls encouraged them to reflect on what aspects of their learning truly had the most impact on them.It opened the door to examining the learning 
process from the ground up, rather than predetermining the core elements of counsellor education content and process and measuring student competency attainment against those elements.

To maintain the focus on multicultural counselling and social justice, students were instructed to "think of your current work with clients, who reflect the diversity of Canadian society through ethnicity, nationality, gender, sexual orientation, socioeconomic status, age, religion, and/or ability" and to "reflect on their needs for effective multicultural counselling and for a range of social justice interventions."They were then asked to identify a positive and a negative learning experience that affected their competence for working with these clients, including learning activities, assignments, tools, processes, as well as less structured or formalized experiences or encounters. When we set up the survey questions and started our analysis of the data, we framed the Cls in terms of helping (positive) or hindering (negative) experiences.What quickly became apparent was that respondents framed negative experiences primarily in terms of what they gained, how those experienced enhanced their awareness, or how they transformed them into important milestones in their competency development. One student commented: "I guess now... when you asked me any like negatives that struck me as a negative.And maybe actually it was kind of a good learning experience in that like how do you challenge people on their beliefs in a way that's not---you know put them down when they're already putting someone else down?You know like it kind of was an interesting exercise in like being able to confront people in a nonthreatening way to just kind of challenge them on their biases.Yeah, I guess it was negative, but also with like a silver lining too."For this reason, we examined the experiences that students saw as negative, holding in mind, that the outcomes of those experiences may have been positive in terms of student learning.

Thedata analysis involved three phases.First, Cls from the online survey were analyzed using NVivo software and categorized according to the primary nature or context of the incident. The purpose was to give us a global picture of what learning processes were most influential, as illustrated in Figure 1.Not surprisingly, the most significant learning experiences stemmed from either students' courses on multicultural counselling or from their practicum experiences.

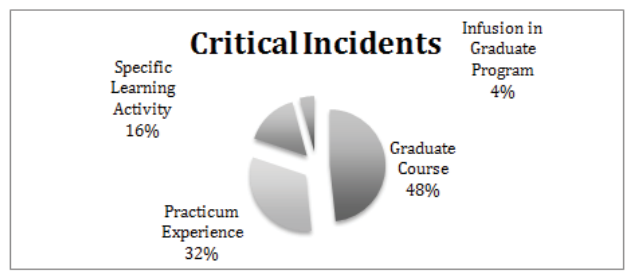

Figure 1. Relative weight of $\mathrm{Cl}$ categories identified by students reflecting on their learning. Practicum supervisor approaches/perspectives has been included under the more general category of practicum experience.

The second phase of analysis involved a more in-depth examination of each of the Cls to identify what specific elements of their course or practicum experience were most impactful.The third phase involved analysis of the follow-up interviews for additional information about the Cls and, in some cases, additional Cls that emerged through that dialogue.A thematic analysis was conducted that resulted in the concept map presented in Figure 2.

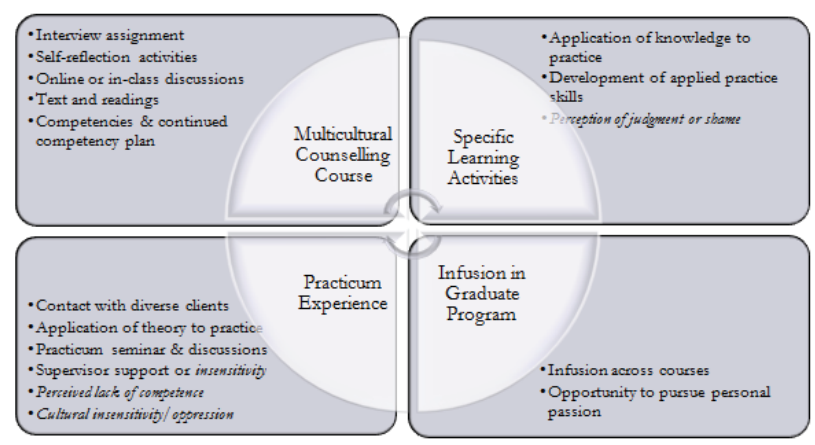

Figure 2. Thematic analysis of students' Cls in the attainment of multicultural and social justice competency. The entries in italics were described as negative $\mathrm{Cls}$, although they may have resulted in positive learning outcomes. 


\section{Results and Discussion}

Rather than reviewing each of the four core categories of $\mathrm{Cls}$ in Figure 2 separately, we will highlight some of the common themes that emerged that provide insight for counsellor educators into what was most critical for students in their learning processes. In doing so, we apply our own knowledge of the programs these students come from to interpret the commonalties across learning activities or contexts.

\subsection{Facilitation and Expectation of Self-Reflection}

A major theme that emerged from our analysis of the Cls was the importance of self-reflection, which is considered central to professional competency (Burnes\& Singh, 2010; Collins, Arthur, \&Wong-Wylie, 2010; Durham \&Glosoff, 2010):"I believe that the course content, assignments, and discussions prompted me to become more in tune with my beliefs, values, and opinions with regards to cultural differences." Students were prompted to move beyond the content of the curriculum to an integration, application, and evaluation of their learning in terms of their own worldview, values, beliefs, and personal cultural identities.Most graduate counselling programs emphasize fostering cultural self-awareness (Cates \&Schaefle, 2009; Pieterse, 2009).Students also noted the emphasis placed on expanding the definition of culture to include ethnicity, age, gender, sexual orientation, religion, socioeconomic status, and ability (Pope \& Arthur, 2009; Sinacore et al., 2011):"The multi-cultural counselling course had a diagram (like a flower) that really helped me reflect on and realize my own culture, and that it is so much more than any minority/majority piece of us; it's all of us."In the course,a great deal of emphasis was placed on the complexity, multiplicity, and fluidity of each individual's cultural identities (Collins, 2010a).Some form of cultural autobiography was noted as one of the most common assignments in graduate courses across a survey of APA accredited programs in the United States (Pieterse et al., 2009).Students remarked on being invited and encouraged "to specifically look at our own cultural make-up and to think about how we were privileged" and "to reflect on our own culture and biases, as well as compare our experience in society with those from different cultural groups," which required "putting on a new set of lenses."Learning activities that specifically targeted reflection on the intersection of both privilege and oppression in students' own experiences have been noted inother studies (Singh et al., 2010)

For students in this study, the process of self-reflection was prompted by course content and assignments, as well as other activities that were part of the learning process.Students in the online course placed particular emphasis on weekly discussion forums: the "discussion forums with instructor and classmates encouraged self-reflection" and "...the discussion forums is when I was able to like, that's the method that helped me to do the self---like build on my own selfawareness and like really integrate what would that look like for me... it was quite often those discussion forums where you really are prompted to kind of---its how you're talking with other people.Like it's just kind of an ongoing dialogue, much like counselling is."These discussion forums also created a safe space for students to examine and, hopefully move through, their biases, assumptions, and personal struggles with the multicultural and social justice content (Palmer \& Parish, 2008; Parra-Cardone, Holtrop, \& Cordova, 2005): “...my classmates would have like a strong reaction to a certain topic... I also remember thinking---and I can't even remember what specifically we were talking about, but I remember thinking boy, this is a really good thing that we're learning this and being able to discuss it amongst each other. Rather than someone being faced with a client with these differences, cultural differences and then having this strong reaction in front of them."

Students also noted the role that their instructors played in facilitating this deeper level of learning about self and other: "The instructors that we had were really good at probing in the right ways at the right times to further our understanding and the meaning behind what we were saying...So the whole system is set up for us to dig deeper, dig deeper.Both externally and internally."'There was encouragement; there was probing; there was questions.It was like---it was modeling excellent counselling, even in the processes."The importance of leadership, modelling, and walking the talk by instructors is commonly referenced in other studies (Caldwell \& Vera, 2010; Durham \&Glosoff, 2010; Kaslow et al., 2004; Singh et al., 2010).In some cases, a single interaction prompted a dramatic change in awareness: "_ pointed out that we (the students) were privileged to even be there. This statement had a significant impact on me personally and as a counsellor. I frequently reflect on this because, up to that point in time, I had thought that I had worked very hard and was simply enjoying the fruits of my labour. I had not previously considered being born in Canada having an impact on whether I had an opportunity to further my education."

The focus in this study was on identifying the types of learning processes that were most memorable or instrumental for students. However, it is sometimes difficult to separate process and outcomes.Self-reflection forms a foundation for the process of professional reflexivity that promotes life-long learning and continued competency 
development (Kaslow et al., 2004; Parra-Cardone et al., 2005; Sammons \& Speight, 2008).Gaining self-awareness is also a well-established foundational domain of multicultural counselling competency (Collins \& Arthur, 2010a, 2010b).

\subsection{Application of Theory and Knowledge to Practice}

Both the online and the face-to-face multicultural counselling courses required students to conduct a cultural interview with a member of a non-dominant population and to apply the theoretical and conceptual learning from the course to the interviewee's experiences. Many students commented on the profound impact this assignment had on them personally and professionally: "I researched refugee experiences and interviewed a client who had come from Ethiopia to Canada as a political refugee. His experience almost exactly paralleled the research. His story was identical to the research... made it very real." "Of most benefit was the multicultural paper I wrote about an Aboriginal elder." "The interview was really impactful in terms of solidifying cultural implications in people's lives... it really solidified the importance of cultural counselling."What appears most significant about this assignment was the opportunity to engage with and learn from the real life experience of another person (Dickson \&Jepsen, 2007; Lewis, 2010; Murray, Pope \& Rowell, 2010).

In both the Cls related to the practicum and specific learning activities, the theme of application of theory or knowledge to practice was reinforced.Many students described specific incidents in which contact with diverse clients had an impact on their competency development (Malott, 2010; Sammons \& Speight, 2008):"I had the opportunity of interacting with clients from very diverse cultural and social backgrounds." "Hearing these women's very different perspectives, life experiences/stories on their culture..." "...it was the practicum component, the real life component there.... Its where everything came together you know."Students were very clear that there was a reciprocal relationship between the theoretical and the applied practice components of their learning (Lewis, 2010):“...that came from that practical learning experience. I could have read about _ in a textbook for a hundred years, but spending an hour and a half specifically focused on culture opened up a whole new understanding, which I wouldn't have paid attention to if it wasn't for that course."Course-work provided the foundation for these experiences, butis viewed as insufficient without real life encounters with diverse members of society (Dickson \&Jepsen, 2007).

The specific learning activities that students selected as Cls were also reflective of the importance of applying knowledge to practice:"Because you're applying, like that seemed to be the theme that keeps going through my head is like the applying of the information in different ways... and that's the learning experience."Students commented on an assignment in the interventions course: "Well, I do think like applying interventions in a socially justice minded way, like just advocating for clients.I guess trying to be---like it's a paper, right, so it's not real.But like being mindful and flexible for client needs and individual needs I guess, yeah.Yeah, I guess it was just really the application of like how would I use this learning with a client.I thought that was really good."They also highlighted elements of the ethics courses, assessment courses, and counselling skills courses that allowed them to engage in application of their learning to simulated practice contexts (Murray et al., 2010):"The expectation was to take it out to the real world.So it never stayed on the computer screen.It was how are you going to apply this? And it asked for a commitment and that was easy for me to make because I was already that way inclined. But I liked the way that it was done. I found that it was a method that really worked for me.It reminded me that okay, don't leave this as an academic thing; do this, right?You want this here and you have the skills now to do it and they gave you the skills to be able to do it."Other writers have identified a range of activities that enable students to apply their learning in practice: for example, micro outreach activities (West-Olatunji, 2010), service learning processes (Miller \&Sendrowitz, 2011; Murray et al., 2010), or engagement in cultural events (Nilsson \& Schmidt, 2005). One of the most common activities was immersion experiences, which were often seen as profoundly transformational experiences for students (Hage, 2005; Hage\& Kenny, 2009; Pieterse et al., 2009).

\subsection{Experiential and Process-Focused Learning}

Diverse learning processes should be used to optimize mastery of complex competencies (Malott, 2010; Pieterse, 2009; Sammons \& Speight, 2008).Students identified elements of the learning process that prompted them to wrestle with their own self-awareness and perspectives, for example, particular experiential exercises:"One experiential exercise was to pretend you were a part of a cultural group for 24 hours... I choose to imagine being a lesbian woman for 24 hours... actually 'experiencing' this increased my awareness more that 'just' reading about it in my texts (not that my textbook wasn't great!)."In a different activity “... we couldn't talk... there was different tables set up and at each table you would go in and we had to play a game without knowing the rules, but there were rules... but you didn't know them beforehand, so you had to figure out that without talking and communicate with the other people at the table and try to play.And to me that was very powerful because I realized yeah, like how difficult and how easy it is to become centering yourself and 
think that---like assume that you know the rules or assume that you know what the other people are trying to do. And then maybe you know, be completely blind to what other people are trying to do.Yeah, that was a really good exercise."In both of these examples, students were required to move beyond the cognitive analysis of particular topics to engage on an affective and personal level, which transformed their consciousness of self and other (Arthur \& Achenbach, 2002; Spanierman, Poteat, Wang, \& Oh, 2008). Experiential or process focused activities are noted in studies related to mastery of multicultural and social justice competencies (Ponterotto, 2011; Vazquez \& Garcia-Vazquez, 2003), with particular emphasis on those that foster an integration of self-reflection and awareness (Alvarez \&Miville, 2003; Arthur \& Achenbach, 2002).A number of other experiential learning processes are highlighted: roleplay, group work, use of vignettes, and guided discussions (Kaslow et al., 2004; McDowell, Fang, Brownlee, Gomez-Young, \&Khanna, 2002; Murray et al., 2010; Ponterotto, 2011; Vazquez \& Garcia-Vazquez, 2003).

The discussion of privilege was one of the few areas where students pointed to negative experiences or negative reactions to particular learning experiences, as they grappled with their own positioning relative to the dominant and nondominant cultures. In both the online and face-to-face versions of the multicultural course, students were engaged in a number of experiential activities targeting privilege and oppression.One student reflected on the lesson on White privilege: "It seemed like a lesson in hypocrisy, that no matter how culturally sensitive I am, how multiculturally competent I become, my knowledge and experiences, values and beliefs - I will always be a white oppressor."Another reacted to the framing of cultural oppression related to First Nations: "The way it was presented as I am to blame and should feel bad for the cultural group I was born into. Very disempowering."It is from these experiences that the perception of judgment and shame noted in Figure 2 emerged.A number of studies recognize the challenge of working with negative emotion that arises from discussions of privilege, including guilt fear anger and resistance (Spanierman et al., 2008; Todd \& Abrams, 2011).The American Psychological Association (APA, 2002), Guidelines on multicultural education, training, research, practice, and organizational change for psychologists, places responsibility on counselling programs for creating a safe environment in which these types of emotions can be managed.For these particular students, there may have been a mismatch between their own development of social justice consciousness and the learning activities (Burnes\&Manese, 2008; Miville et al., 2009). Todd and Abrams (2011) argued that, in the context of mastery of multicultural and social justice competencies, it is important to remember that authentic engagement is the goal, because this is what will lead to personal change.Experiential learning needs to be adequately facilitated and debriefed to help students manage their emotional reactions, sense of dissonance, and apply their learning to practice (Arthur \& Achenbach, 2002).

\subsection{Direct and Indirect Encounters with Diversity}

The fourth theme that runs through the analysis of the Cls is the encounter, either directly or indirectly, with cultural diversity.Students noted their personal and professional transformation through directed readings and other course content and through their contact with culturally different individuals or groups.The culture-infused counselling model formed a conceptual foundation for both online and face-to-face classes (Arthur \& Collins, 2010).The textwas often referenced forits conceptual framework for multicultural counselling and social justice competency as well as chapters on various nondominant groups.Students noted the particular emphasis on the fluidity and intersectionality of various nondominant cultural identities:"...the chapters... provided you with a sense of what could be going on for particular... non-dominant groups... And I think it's written in a way that it's clear that it's not---there are guidelines and not necessarily saying oh, this is the way these people are, which I think is wrong.Would be again, doing a huge assumption, right?So in that sense it was a really helpful book."The most significant elements of the text for students were the authors'personal experiences, as well as the case studies and vignettes of clients, sprinkled throughout the book, which fostered diversity and multiplicity of perspectives (Fouad\& Arredondo, 2007; McDowell et al., 2002; Pieterse et al., 2009) andprovided an indirect encounter with cultural diversity: "...reading about the specific case studies and the perceptions of the individuals that allowed me to see that they have experience their world so very differently than I have" and"I remember reading the vignettes in the book, and thinking: wow, I never thought about this."

These indirect cultural encounters laid a foundation for thedirect encounters with clients and others, particularly during the practicum. There is general consensus in the literature that one of the central needs of graduate students is applied practice experience with the multicultural and social justice competencies (Burnes\& Singh, 2010; West-Olatunji, 2010).For many students, it was the direct interaction with individuals, families, or groups from diverse cultural backgrounds that provided the most transformative learning experiences (Malott, 2010; Sammons \& Speight, 2008): "I had the opportunity of interacting with clients from very diverse cultural and social backgrounds. I asked these clients to be my guides;" "One example of an important learning experience was working with a client from a different culture for whom religion was also an important factor to consider in regards to an important life decision;" or "...I had the 
opportunity to co-counsel a lesbian couple, for a few sessions, with my supervisor."It was through these encounters that their class-based learning crystalized and became most meaningful (Dickson \&Jepsen, 2007): "So I think it was the practicum component, the real life component there.... Its where everything came together you know;" "the practicum experience I had, where the client was struggling with their cultural identity was pretty significant because it made those cultural identity phases real."

Most students were fortunate to have exposure to culturally diverse clientele during their practica.For others, however, it was the lack of cultural diversity that became a $\mathrm{Cl}$ in their professional development: "I probably could have benefitted from direct exposure and immersion in to a group with different background."It may be important for counsellor education programs to foster practicum placements with a multicultural and social justice focus (Burnes\& Singh, 2010).Ifcounsellor educators agree that competency in multicultural counselling and social justice are core to professional practice, it may become increasingly important to actively shape the nature of our graduate practicum experiences to ensure that students gain exposure and supervision in working with a wide range of cultural groups (Kaslowet al., 2004; Miller \&Sendrowitz, 2011).It is certainly not possible to have direct applied practice experience with all aspects of culture; however, students noted thatsharing their experiences in the practicum seminars provided another indirect encounter with diversity: "...it was just a really neat way to again hear from other people and what are their experiences with various populations" and "... lots of discussion time with each other as classmates about different populations that we were working with... then like also, not challenging each other, but you know, like being able to kind of draw out well, what would it have been like if we had gone this way or asked them about that?"These practicum seminars provided a space for students to bring together practice and reflection (Buckley \&Foldy, 2010).

Student encounters with diversity were not always positive; however, even negative encounters provided critical learning experiences for students.In some cases, students observed clients' experiences of cultural oppression in the context of their lives: "Not only can oppression be present in visible minorities, disabled etc. I have seen various clients who have been oppressed based on social class, educational background, and geographic location."Caldwell and Vera (2010) argued that such exposure to social injustices is important to students' learning processes. Ironically, the examples of cultural oppression of clients were oftenwithin the context of the counselling organization: "A client was given an assessment tool and without recognition of his cultural background the results would have been incorrect, when considering cultural background, particularly the education system, further assessment was deemed necessary and hence a different diagnosis resulted."'I had a client who was in an arranged marriage. In deciding on an intervention, a lot of focus was laid on the issue of the arranged marriage...I believe that the team had viewed this client's concerns from their own cultural perspective other than the client's. The team saw the arranged marriage as the genesis of her concerns but she didn't so I felt that we as the team had not met the client where she was, culturally."One student concluded: "I think the greatest learning experience came from realizing the limitations of the actual organization one works in as a counsellor and trying to understand the protocol to meet client needs."For a few students differences in perspective or approach between them and the practicum supervisor, for example,posed a barrier to applying their multicultural and social justice consciousness:“.... when we met to discuss my 'multicultural lens' I felt that my supervisor had a very narrow view of a culturally sensitive, multiculturally informed practitioner. While she noted she had seen my practice improve because I was now aware of my personal bias with regards to gender... she did not seem to understand that this was just a small aspect of a MCC.".It may be important for counsellor education programs to take a strongerlead in orienting practicum supervisors and placements to the conceptual foundations of multicultural counselling and social justice practice (Burnes\&Manese, 2008; Grus, 2009; Pack-Brown, Thomas, \& Seymour, 2008; Talleyrand, Chung \&Bemak, 2006).

\section{Reflections and Future Directions}

The purpose of this paper has been to examine the Cls that students identified as significant to their learning about multicultural counselling and social justice. We wanted to know what learning experiences students, towards the end of their programs, reflected back on as turning points or aha moments that contributed to their competency development or, in some cases, posed barriers to their learning.Not surprisingly, most students highlightedlearning processes within their multicultural counselling course (Sammons \& Speight, 2008; Talleyrand et al., 2006), in which the foundation of multicultural and social justice competencies was laid, and in their practicum experience, where they came face-to-face with diversity and had the opportunity to translate their learning into practice (Dickson \&Jepsen, 2007; Lewis, 2010; Murray et al., 2010).The four core themes that emerged across the Cl's in this study reinforcedelements of effective counsellor education for multicultural counselling and social justice: application of theory to practice, fostering of selfawareness, engagement of affect through experiential exercises, and exposure to diversity. 
However, it is important not to assume from these observations that we have arrived.Only four percent of the Cls fit under the theme of infusion of multicultural counselling and social justice perspective throughout the graduate program. Some students in this study noted: "...all of my graduate courses integrated multicultural awareness and cultural sensitivity;" "...multiculturalism was certainly woven throughout all of the courses that I took;" " $\ldots$ it was integrated into it...It was emphasized;" and "each class we touched upon diversity."Most students, however, linked their learning mainly to the multicultural counselling course and practicum, with some mention of ethics, interventions, and counselling skills courses. The positioning of the multicultural course early in the program provided an opportunity for students to carry forward and apply their learning in other courses (Lewis, 2010; Sammons \& Speight, 2008; Talleyrand et al., 2006): "I'm pretty aware that my social justice understanding really developed in my Master's degree, specifically in the culture infused course. We did it early on in the course and it just kind of set a tone for me to be conscious of the languaging that I was using and the vocabulary I'm using with clients."Another student reflected on the importance of that course in shaping her/his overall learning experience: "It was almost like bathing in it for thirteen weeks. It infused me with the capacities, the desires, the capability to do what I was already inclined to do, but did not have the skills to do.And I feel like I have way, way more skills to work in the social justice realm than I had before."Students then pursued that personal passion by tailoring their assignments in other courses throughout their program:"' just felt like it really set a tone for me to be aware of the multicultural piece within each other course."Given the authors' knowledge of the two graduate programs, we hypothesize that some of the experiences of infusion of multicultural and social justice themes throughout the graduate programs may be a reflection of the students' own initiative: "Like literally, I think I tied it into each of my courses.Yeah, like in some way, writing in papers, like I know that I did.But those are the ones that kind of stand out as focusing on social justice and multiculturalism."The competency-based focus of the multicultural course may have facilitated students to carry forward the lens of multicultural and social justice practice throughout their program: "...they also provided a thorough list of competencies around multiculturalism.And that was be practical in terms of understanding you know all the different areas of becoming a multicultural counsellor and what that might mean in practice." The importance of competency-based training models has also received general consensus in the literature (Grus, 2009; Kaslow et al., 2004; Miville et al., 2009):"'One of the last things that we did in the course was a professional development plan and it linked the plan to all the competencies that we felt we wanted to enhance...And I found that was extremely useful because it made me focus on specifics and... when I go back in and look at it again l'll be happy to see that a bunch of the work that I have been doing in the last couple of years since the course has been working towards following that plan." There is general consensus that multicultural and social justice orientation and applied practice skills should be infused throughout the entire project program (Fouad\& Arredondo, 2007; Green et al., 2008; Lewis, 2010; Pack-Brown et al., 2008). This expectation is also reflected in the American Counseling Association (2005) Code of ethics and the APA (2002), Guidelines on multicultural education, training, research, practice, and organizational change for psychologists.Less clear expectations are provided in the Canadian regulatory guidelines. Most graduate programs still follow a single course design for delivery of multicultural and social justice content (Lopez-Baez \&Paylo, 2009).

A noteworthy absence from the Cls was indirect or direct engagement with social justice roles and activities. There was no mention of engagement in advocacy, observation of systems change strategies with the practicum contexts, or other forms of social justice action (Alberta \& Wood, 2009; Cates \&Schaefle, 2009; Hage, 2005; Pieterse, 2009; Pieterse et al., 2009; Ratts\&Hutchkins, 2009).Students were transformed by consciousness-raising related to, and observations of, social injustice; however, they did not describe meaningful social justice learning experiences.Although multicultural counselling and social justice are inextricably intertwined (Collins, 2010a;Ratts, 2011), it may be interesting in future examinations of students' critical learning incidents to focus more directly and exclusively on social justice awareness and practice.There are strong suggestions in the literature that this is an area in which it is particularly important to provide modeling (Mintz et al., 2009; Winterowd, Adams, Miville, \&Mintz, 2009), applied practice skill development (Alberta \& Wood, 2009; Cates \&Schaefle, 2009; Pieterse, 2009; Ratts\&Hutchkins, 2009), and purposeful supervised practicum experiences (Burnes\& Singh, 2010; Lewis, 2010).

The student perspectives derived from the data in the current study provide a window from which to consider what is meaningful for students, what content and learning processes to keep, and areas for growth in the development of teaching and learning pedagogy for multicultural counselling.Although the perspectives in this study are based on a volunteer sample from two graduate programs, they provide one of the few studies that captured not only what was useful in graduate curriculum, but also how students learned these competencies. Future research is needed that expands upon best practices for fostering multicultural and social justice awareness, knowledge, and skills. 


\section{References}

Alberta, A., \& Wood, A. (2009). A practical skills model for effectively engaging clients in multicultural settings. The Counseling Psychologist, 37(4),564-579.doi:10.1177/0011000008326231

Alvarez, A. N., \&Miville, M. E. (2003). Walking a tightrope: Strategies for teaching undergraduate multicultural counseling courses. In D. B. Pope-Davis, H. L.K. Coleman, W. M. Liu, \& R. L. Toporek (Eds.), Handbook of multicultural competencies in counseling and psychology (pp. 528-545). Thousand Oaks, CA: Sage.

American Counseling Association. (2005). ACA code of ethics. Retrieved from http://www.counseling.org/Resources/CodeOfEthics/ TP/Home/CT2.aspx

American Psychological Association. (2002). Guidelines on multicultural education, training, research, practice, and organizational change for psychologists. Retrieved from http://www.apa.org/pi/multiculturalguidelines.pdf

Arthur, N., \& Achenbach, K. (2002). Developing multicultural counselling competencies through experiential learning. Counselor Education and Supervision, 42(1), 2-14. Retrieved from http://ca.wiley.com/

Arthur, N., \& Collins, S. (Eds.). (2010). Culture-infused counselling (2nd ed.). Calgary, AB: Counselling Concepts.

Arthur, N., \& Collins, S. (2011). Infusing culture in career counselling. Journal of Employment Counseling [Special Issue], 48(4). 147-149. doi:10.1002/j.2161-1920.2011.tb01098.x

Arthur, N., Collins, S., Marshall, C., \& McMahon, M. (2013). Social justice competencies and career development practices.Canadian Journal of Counselling and Psychotherapy.47(2), 136-154

Arthur, N., Collins, S., McMahon, M., \& Marshall, C. (2009). Career Practitioners' views of social justice and barriers for practice. Canadian Journal of Career Development, 8(1), 22-31. Retrieved from http://www.ceric.ca/cjcd/

Buckley, T. R., \&Foldy, E. G. (2010). A pedagogical model for increasing race-related multicultural counseling competency.The Counseling Psychologist, 38 (5), 691-713.doi:10.1177/0011000009360917

Burnes, T. R., \&Manese, J. E. (2008). Social justice in an accredited internship in professional psychology: Answering the call. Training and Education in Professional Psychology, 2(3), 176-181. doi:10.1037/1931-3918.2.3.176

Burnes, T. R., \& Singh, A. A. (2010). Integrating social justice training into the practicum experience for psychology trainees: Starting earlier. Training and Education in Professional Psychology, 4(3), 153-162. doi:10.1037/a0019385

Butler-Byrd, N., Nieto, J., \& Nieto Senour, M. (2006). Working successfully with diverse students and communities: The communitybased block counselor preparation program. Urban Education,41(4), 376-401. doi:10.1177/0042085906289706

Butterfield, L., Borgen, W., Amundson, N., \&Maglio, A. (2005). Fifty years of the critical incident technique: 1954-2004 and beyond. Qualitative Research, 5, 475-497.doi:10.1177/1468794105056924

Caldwell, J. C., \& Vera, E. M. (2010).Critical incidents in counseling psychology professionals' and trainees' social justice orientation development.Training and Education in Professional Psychology, 4(3), 163-176. doi:10.1037/a0019093

Cates, J., \&Schaefle, S. (2009). Infusing multicultural training into practicum. Journal of Counseling Research and Practice, 1(1), 32-41. Retrieved from http://www.mscounselor.org

Collins, S. (2010a). The complexity of identity: Appreciating multiplicity and intersectionality. In N. Arthur \& S. Collins (Eds.).Cultureinfused counselling (2nd ed., pp. 247-258).Calgary, AB: Counselling Concepts.

Collins, S. (2010b). Women on the margins: Honouring multiple and intersecting cultural identities. In L. Ross. (Ed.). Counselling Women: Feminist Issues, Theory and Practice(pp. 21-50). Toronto, Ontario: Canadian Scholars' Press / Women's Press.

Collins, S., \& Arthur, N. (2010a). Culture-infused counselling: A fresh look at a classic framework of multicultural counselling competencies. Counselling Psychology Quarterly, 23(2), 203-216. doi:10.1080/09515071003798204.

Collins, S., \& Arthur, N. (2010b). Culture-infused counselling: A model for developing multicultural competence. Counselling Psychology Quarterly, 23(2), 217-233. doi:10.1080/09515071003798212.

Collins, S., Arthur, N., \& Brown, C. (2013).Counsellors and Practicum Supervisor Critical Incidents in the Development of Multicultural and Social Justice Competency.Manuscript in preparation.

Collins, S., Arthur, N., Brown, C., \& Kennedy, B. (2013a).Counsellor and Supervisor Views of Multicultural and Social Justice Competency Training. Manuscript submitted for publication.

Collins, S., Arthur, N., Brown, C., \& Kennedy, B. (2013b).Student Perspectives on Graduate Education Facilitation of Multicultural and Social Justice Competency.Manuscript in preparation.

Collins, S., Arthur, N., \&Wong-Wylie, G. (2010). Enhancing reflective practice in multicultural counseling through cultural auditing. Journal of Counseling \& Development, 88(3), 340-347. Retrieved from http://www.counseling.org/

Constantine, M., Hage, S., Kindaichi, M., \& Bryant, R. (2007).Social justice and multicultural issues: Implications for the practice and training of counsellors and counseling psychologists. Journal of Counseling and Development, 85(1), 24-30. Retrieved from http://onlinelibrary.wiley.com/

Dickson, G. A., \&Jepsen, D. A. (2007). Multicultural Training Experiences as Predictors of Multicultural Competencies: Students' perspectives. Counselor Education \& Supervision, 47(2), 76-95. Retrieved from http://www.counseling.org/

Durham, J., \&Glosoff, H. (2010). From passion to action: Integrating the ACA advocacy competencies and social justice into counselor education and supervision. In M. Ratts, R. Toporek, \& J. Lewis. ACA Advocacy competencies: A social justice framework for counsellors (pp. 139-149). Alexandria, VA, US. American Counseling Association.

Fouad, N. A., \& Arredondo, P. (2007). Becoming culturally oriented: Practical advice for psychologists and educators. Washington, DC: American Psychological Association. 
Fowers, B. J., \&Davidov, B. J. (2007). The virtue of multiculturalism: Personal transformation, character, and openness to the other. American Psychologist, 61(6), 581-594.doi:10.1037/0003-066X.61.6.581

Green, E., McCollum, V., \& Hays, D. (2008). Teaching advocacy counseling within a social justice framework: Implications for school counselors and educators. Journal for Social Action in Counseling \& Psychology, 1(2), 14-30. Retrieved from http://jsacp.tumblr.com/

Greenleaf, A. \& Williams, J. (2009). Supporting social justice Advocacy: A paradigm shift towards an ecological perspective. Journal for Social Action in Counseling and Psychology, 2(1), 1-14. Retrieved from http://jsacp.tumblr.com/

Grus, C. (2009). Implications of the counseling psychology model Training Values Statement addressing diversity for education and training in professional psychology. The Counseling Psychologist, 37(5), 752-759.doi:10.1177/0011000009334432

Hage, S. M. (2005). Future considerations for fostering multicultural competence in mental health and educational settings: Social justice implications.In M. Constantine, \& D. W. Sue (Eds.), Strategies for Building Multicultural Competence in Mental Health and Educational Settings (pp. 285-299). Hoboken, NJ: Wiley.

Hage, S. M., \& Kenny, M. E. (2009). Promoting a social justice approach to prevention: Future directions for training, practice and research. Journal of Primary Prevention, 30(1), 75-87.doi:10.1007/s10935-008-0165-5

Kaslow, N. J., Borden, K. A., Collins, F. L. Jr., Forrest, L., Illfelder-Kaye, J., Nelson, P. D., \&Rallo, J. S. (2004). Competencies conference: Future directions in education and credentialing in professional psychology. Journal of Clinical Psychology, 60(7), 699-712.doi:10.1002/jclp.20016

Leong, F. T. L. (2010). A cultural formulation approach to career assessment and career counseling: Guest editor's introduction. Journal of Career Development, 37, 375-390.doi:10.1177/0894845310363708

Lewis, B. L. (2010). Social justice in practicum training: Competencies and developmental implications. Training and Education in Professional Psychology, 4(3), 145-152. doi:10.1037/a0017383

Lopez-Baez, S. I., \&Paylo, M. J. (2009). Social justice advocacy: Community collaboration and systems advocacy. Journal of Counseling \& Development, 87(3), 276-283. Retrieved from http://www.counseling.org

Malott, K. M. (2010). Multicultural counselor training in a single course: Review of research. Journal of Multicultural Counseling and Development, 38(1), 51-63. Retrieved from http://www.wiley.com

McDowell, T., Fang, S., Brownlee, K., Gomez-Young, C., \&Khanna, A. (2002). Transforming a MFT program: A model for enhancing diversity. Journal of Marital and Family Therapy, 28(2), 179-191.doi:10.1111/j.1752-0606.2002.tb00355.x

Miller, M. J., \&Sendrowitz, K. (2011). Counseling psychology trainees' social justice interest and commitment. Journal of Counseling Psychology, 58(2), 159-169.doi:10.1037/a0022663

Mintz, L., Jackson, A., Neville, H., Illfelder-Kaye, J., Winterowd, C., \& Loewy, M. (2009). The need for a counseling psychology model training values statement addressing diversity. The Counseling Psychologist, 37(5), 644-675.doi:10.1177/0011000009331931

Miville, M., Duan, C., Nutt, R. L., Waehler, C. A. Suzuki, L., Pistole, C., Arredondo, P.,...Corpus, M. (2009). Integrating practice guidelines into professional training implications for diversity competence.The Counseling Psychologist 37(4), 519563.doi:10.1177/0011000008323651

Murray, C. E., Pope, A. L., \& Rowell, P.C. (2010). Promoting counseling students' advocacy competencies through service-learning. Journal for Social Action in Counseling and Psychology, 2(2), 29-47. Retrieved from http://jsacp.tumblr.com/

Nilsson, J. E., \& Schmidt, C. K. (2005). Social justice advocacy among graduate students in counseling: An initial exploration. Journal of College Student Development, 46(3), 267-279. doi:10.1353/csd.2005.0030

Pack-Brown, S., Thomas, T., \& Seymour, J. (2008). Infusing Professional Ethics Into Counselor Education Programs: A Multicultural/Social Justice Perspective. Journal of Counseling \& Development, 86(3), 296-302. Retrieved from: http://www.counseling.org/

Palmer, A., \& Parish, J. (2008). Social justice and counselling psychology: Situating the role of graduate student research, education, and training. Canadian Journal of Counselling and Psychotherapy, 42(4), 278-293.Retrieved fromhttp://cjc-rcc.ucalgary.ca/cjc/

Parra-Cardone, J.R., Holtrop, K., \& Cordova, D. (2005). "We are clinicians committed to cultural diversity and social justice": Good intentions that can wane, Guidance \& Counseling, 21(1), 36-46. Retrieved from www.utpress.utoronto.cal

Pieterse, A. L., (2009). Teaching antiracism in counselor training: Reflections on a course. Journal of Multicultural Counseling and Development, 37(3), 141-152. Retrieved from http://www.wiley.com

Pieterse, A. L., Evans, S., Risner-Butner, A., Collins, N., \&Mason, L. (2009). Multicultural competence and social justice training in counseling psychology and counselor education. The Counseling Psychologist, 37(1), 93-115.doi:10.1177/0011000008319986

Ponterotto, J. G. (2011). Research and training on White dialectics: Some next steps. The Counseling Psychologist, 39(3), 396404.doi:10.1177/0011000010388423

Pope, J., \& Arthur, N. (2009). Socioeconomic status and class: A challenge for the practice of psychology in Canada. Canadian Psychology, 50(2), 55-65.doi:10.1037/a0014222.

Ratts, M. (2011). Multiculturalism and social justice two sides of the same coin.Journal of Multicultural Counseling \& Development, 39(1), 24-37. Retrieved from http://www.counseling.org

Ratts, M., \&Hutchkins, M. (2009). ACA Advocacy Competencies: Social justice advocacy at the client/student level. Journal of Counseling and Development, 87(3), 269-276.Retrieved from http://onlinelibrary.wiley.com/

Sammons, C., \& Speight, S. (2008). A Qualitative investigation of graduate-student changes associatedwith multicultural counseling courses. The Counseling Psychologist, 36(6), 814-838.doi:0.1177/0011000008316036 
Sinacore, A., Borgen, W. A., Daniluk, J., Kassan, A., Long, B. C., \&Nicol, J. (2011). Canadian counselling psychologists' contributions to applied psychology.Canadian Psychology, 52(4), 276-288.doi:10.1037/a0025549

Singh, A. A., Hofsess, C., Boyer, E., Kwong, A., Lau, A., McLain, M. \&Haggins, K. L. (2010). Social justice and counseling psychology: Listening to the voices of doctoral trainees. The Counseling Psychologist, 38(6), 766-795.doi:10.1177/0011000010362559

Smith, T. B., Constantine, M. G., Dunn, T. W., Dinehart, J. M., \& Montoya, J. A. (2006). Multicultural education in the mental health professions: A meta-analytic review. Journal of Counseling Psychology, 53(1), 132-145.doi:10.1037/0022-0167.53.1.132

Spanierman, L. B., Poteat, V. P., Wang, Y., \& Oh, E. (2008). Psychosocial costs of racism to White counselors: Predicting various dimensions of multicultural counseling competence.Journal of Counseling Psychology, 55(1), 75-88.doi:10.1037/00220167.55.1.75

Talleyrand, R. M., Chung, R. C., \&Bemak, F. (2006). Incorporating social justice in counsellor training programs. In R. L. Toporek, L. H., Gerstein, N. A., Fouad, G. Roysircar, \& T. Israel (Eds.). Handbook for social justice in counseling psychology: Leadership, vision, and action (pp. 45-58). Thousand Oaks, CA; Sage.

Todd, N. R., \& Abrams, E. M. (2011). White dialectics: A new framework for theory, research, andpractice with White students. The Counseling Psychologist, 39(3), 353-395.doi:10.1177/0011000010377665

Toporek, R. L., \& McNally, C. J. (2006). Social justice training in counseling psychology: Needs and innovations. In R. L. Toporek, L. H., Gerstein, N. A., Fouad, G. Roysircar, \& T. Israel (Eds.). Handbook for social justice in counseling psychology: Leadership, vision, and action (pp. 37-43). Thousand Oaks, CA; Sage.

Vazquez, L. A., \& Garcia-Vazquez, E. (2003). Teaching multicultural competence in the counseling curriculum. In D. B. Pope-Davis, H. L.K. Coleman, W. M. Liu, \& R. L. Toporek (Eds.), Handbook of multicultural competencies in counseling and psychology (pp. 546-561). Thousand Oaks, CA: Sage.

Vera, E. M., \& Speight, S. L. (2003). Multicultural competence, social justice, and counseling psychology: Expanding our roles. The Counseling Psychologist, 31(3), 253-272.doi:10.1177/0011000003031003001

West-Olatunji, C. (2010). If not now, when? Advocacy, social justice, and counsellor education.Counseling and Human Development, 42(8), 1-12. Retrieved from http://www.counseling.org/

Winterowd, C. L., Adams, E. M., Miville, M. L., \&Mintz, L. B. (2009). Operationalizing, instilling, and assessing counseling psychology training values related to diversity in academic programs. The Counseling Psychologist, 37(5), 676704.doi:10.1177/0011000009331936

Zalaquett, C., Foley, P., Tillotson, K., Dinsmore, J., \& Hof, D. (2008). Multicultural and social justice training for counselor education programs and colleges of education: Rewards and challenges.Journal of Counseling and Development, 86(3), $364-372$. Retrieved from http://onlinelibrary.wiley.com/ 